Revolution in Development 



\title{
Revolution in Development
}

\author{
MEXICO AND THE GOVERNANCE \\ OF THE GLOBAL ECONOMY
}

Christy Thornton

阤

U N IVERSITY OF CALIFOR N A PRES 
University of California Press

Oakland, California

(C) 202 I by Christy Thornton

Library of Congress Cataloging-in-Publication Data

Names: Thornton, Christy, author.

Title: Revolution in development : Mexico and the governance of the global economy / Christy Thornton.

Description: Oakland, California : University of California Press, [202I] | Includes bibliographical references and index.

Identifiers: LCCN 2020021294 (print) | LCCN 2020021295 (ebook) | ISBN 9780520297159 (cloth) | ISBN 9780520297166 (paperback) | ISBN 9780520969636 (epub)

Subjects: LCSH: International economic relations. | Mexico-Economic policy-History-2oth century.

Classification: LCC HCI35 .T535 202I (print) | LCC HCI35 (ebook) | DDC $337-\mathrm{dc} 23$

LC record available at https://lccn.loc.gov/2020021294

LC ebook record available at https://lccn.loc.gov/202002I295

Manufactured in the United States of America

$\begin{array}{llllllllll}29 & 28 & 27 & 26 & 25 & 24 & 23 & 22 & 21 & 20\end{array}$

I0 $9 \begin{array}{lllllllll}10 & 8 & 7 & 6 & 5 & 4 & 3 & 2 & \text { I }\end{array}$ 
For Gail 
